\title{
Knowledge Mapping \& Working with Difficult to Reach Groups: Sex Work Knowledge in the City
}

\author{
Christopher Hartworth $^{1}$, Joanne Hartworth ${ }^{1}$, Ian Convery ${ }^{2}$ \\ ${ }^{1}$ Barefoot Research \& Evaluation, Newcastle upon Tyne, UK \\ ${ }^{2}$ University of Cumbria, Penrith, UK \\ Email: ian.convery@cumbria.ac.uk
}

Received January $14^{\text {th }}, 2012$; revised February $16^{\text {th }}, 2012$; accepted February $28^{\text {th }}, 2012$

\begin{abstract}
This paper considers the lessons learned from researching sex markets in Northumberland and Tyne and Wear, UK. It is based on a knowledge mapping approach, working with professionals in local authorities, charities and the police involved with sex markets in the Northumbria Police Area. The research identified that the visible sex market in the area was part of a much bigger exchange system. A number of important themes emerged from the findings and strong links were found between sex work and issues such as drug misuse, mental and physical health and the use of services. A key theme was that many sex workers suffered economic, housing, health, social and physical vulnerabilities. These themes have implications for local statutory and voluntary services. However, despite increasing calls for more open public debate on sex work and prostitution, our experience is that this remains a complex and restricted research area in the UK. The knowledge mapping approach detailed in this paper represents an important step in furthering the debate.
\end{abstract}

Keywords: Knowledge Mapping; Sex Markets; Prostitution

\section{Introduction: Researching Sex Markets}

Before any service provision decisions are made regarding sex workers, a detailed mapping of the local situation should be undertaken to establish what type of sex market there is. However, researching sex markets is difficult. The researcher may face hostile and volatile environments, unsociable working hours and the need for a wide range of research skills including negotiation, conflict management and being able to 'keep quiet' when necessary (Sanders, 2005). It is doubly difficult when the population is unknown (Pyett, 1998) and participant lifestyles are chaotic and, of necessity, hidden (Mosedale, 2009).

As Cusick et al. (2009) note, it is very difficult to establish a firm estimate of the UK sex working population ${ }^{1}$. Part of the reason for this relates to a muddled legal system. In the UK there have been recent debates about reforming existing prostitution laws (Home Office, 2006) and some discussion regarding moving towards a "tolerance zone system" (Howell et al., 2008; Hubbard et al., 2008; McKeganey, 2006; West, 2000). The present situation is paradoxical, for whilst prostitution is not illegal, street walking, curb crawling and brothels are illegal, thus it is impossible for sex workers to sell sex without breaking a number of laws (Hubbard, 2004). Moreover, whilst prostitution may not be illegal, a range of legislation and measures (such as The Sexual Offences Act 2003; Policing and Crime Bill 2009; AntiSocial Behavior Orders and Acceptable Behavior Contracts) makes providing sex in exchange for money

\footnotetext{
${ }^{1}$ We use sex worker and sex work as general headings and they include the range of different types of sex worker. By sex work we refer to male and female workers who perform a sexual act in exchange for a commodity, for example drugs, money, alcohol, status, goods, accommodation. After Cameron (2004), we use the term market to signify that something is being bought and sold. We recognize, however, that there is much debate and controversy about the naming of those involved in sex markets.
}

difficult and dangerous (West, 2000; Sanders, 2004, 2005; Hubbard, 2004).

Writing in The Guardian newspaper, Rothschild (2009) argues that much of the debate around the sex industry in the UK is infused with moral panic and states that when women are presented as victims, they elicit sympathy; but when they assert their agency, they are viewed as a threat to the moral fabric.

Yet sex markets are also an important sector within the black economy (Sanders, 2008; Moffat \& Peters, 2004). Ward et al. (2005) indicate that approximately one in ten men (aged 16 - 44) in Britain have paid for sex, and an earlier study by Coyle (2001) estimated that prostitution in the UK was worth around $£ 770 \mathrm{~m}$ a year, which at the time equated to $13 \%$ of gross domestic product, or about one pound in every eight, and lost tax revenues of some $£ 250 \mathrm{~m}$ (if legalized). As a comparison, De Speigel newspaper (2011) reports how Bonn has become the first city in Germany to introduce meters for sex workers as a means of extending a general tax on prostitution beyond brothels to the city streets. The meters were installed in an industrial area near the center of town used by freelance sex workers to solicit clients, with each sex worker paying €6 per night worked, regardless of how many customers they have. Those repeatedly caught without a ticket they can be fined. Bonn authorities estimated that the prostitution tax (including meter payments) would bring in €300,000 in 2011.

A range of methodologies have been used to investigate sex workers ${ }^{1}$ (Cusick et al., 2009). These including observations and interviews (Pasco, 2002; Port \& Bonilla, 2000), questionnaires (Belis et al., 2007), autobiographical narratives (Annadale, 2005; Efthimiou-Mordant, 2002; Landale, 2005), diaries (Gysels et al., 2002), unstructured interviews (Mosedale, 2009), semi-structured interviews (McKeganey, 2006) and ethnographic approaches (Sanders, 2005, 2006). In particular, the 
ethnographic approach has almost become the de rigueur for research into sex work and encourages researchers to immerse themselves in the sub-cultural world of the sex industry, to observe, to get close to those involved, and sometimes to participate (Wahab, 2003).

All these approaches are potentially useful and valid, but they are also often time consuming and expensive and may not fit the needs of voluntary or statutory service review or evaluation, which often require a rapid appraisal approach. Moreover, many researchers outside academic institutions and statutory agencies (for example, researchers working for voluntary sector organizations or small consultancy groups) simply do not have the resources to meet the often complex and time-consuming requirements associated with sex market fieldwork, where formal ethical clearance, risk assessment and consent require careful consideration and scrutiny by formal panels. We are not arguing against such requirements (indeed, if ever a research arena required careful ethical consideration and risk assessment it is sex work), but rather that an unfortunate consequence of what might be termed "academic formality" is often to limit rather than enable public debate on sex work as discourse tends to be restricted and knowledge hegemonic. This, we would argue, ultimately helps keep sex markets hidden, and contributes to the lack of service provision and policy development. By compareson knowledge mapping can provide a quick, accurate and inexpensive overview of sex markets and information gathered in this way can be triangulated with data from other sources to inform areas such as service development and the commissioning of longitudinal research.

As McKeganey (2006) notes, despite a recent interest in prostitution research we know less than we might wish about sex workers in the UK. Our research, which was funded by the Northern Rock Foundation, was developed to investigate the extent, nature and characteristics of the sex market and sexual exploitation in Northumberland and Tyne and Wear (Figure 1 and Table 1) where such markets are not openly visible. Our emphasis in this paper is not the social theory of sex work but rather an applied sociological approach (knowledge mapping), which we believe has great potential for sociological research with hard to reach populations. Whilst our focus is methodological, we also report some of the main findings from our study, cross-referenced with the findings from a peer-led project (Voices Heard, 2007) conducted at the same time as our research $^{2}$ to "validate" our approach.

Previous research by the authors (Hartworth et al., 1998) identified a thriving (though small) market of independent sex workers trading through local papers and adult contact magazines in Northumberland and Tyne \& Wear, UK (Figure 1 indicates the study area and Table $\mathbf{1}$ discusses study area char

\footnotetext{
${ }^{2}$ The Voices Heard project (2007), which including ex-sex workers and ex-problematic drug users as researchers, employed a 'privileged access' approach (Griffiths et al, 2006) to investigate sex markets and explore issues relating to accommodation, criminality, drug use, health, survival and violence. This peer-led approach to researching sex markets had been used successfully in other areas (Pyett, 1998; Elmore-Meegan et al., 2004). In Australia, Pyett trained sex workers as researchers and found that using this method, the overwhelming majority of workers were supportive and that refusal to participate was rare (Pyett, 1998:12). In a study of sex workers in Kenya, Elmore-Meegan et al. (2004) recruited peer interviewers to increase a sense of ownership of the research by both interviewers and participants, and to ensure that the interviews were carried out in as nonjudgmental a way as possible. They also found that as interviewers were familiar with sex work, they were less likely to accept implausible answers without attempting to get clarification (see also Boynton, 2002).
}

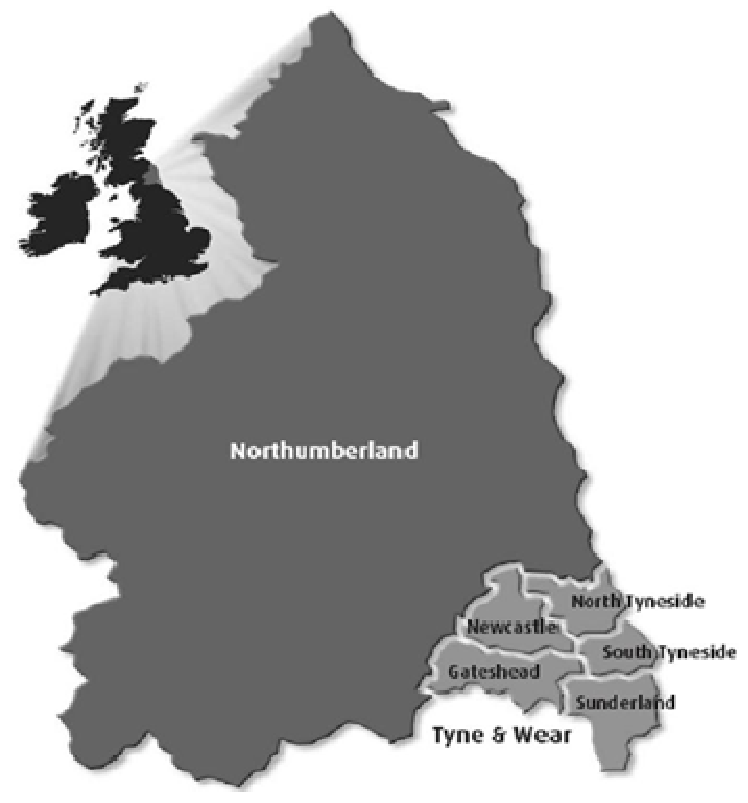

Figure 1.

Map of study area.

Table 1.

Characteristics of the study area.

Population of almost 190,500 and borders the river
Tyne at its northern edge. The 2004 Index of Multiple
Deprivation (IMD, 2004) ranks Gateshead as the 26
most deprived district in England (out of a total of
Gateshead
354) and almost half the population live in the top 20
most deprived areas.

$\begin{array}{ll}\text { Regional capital, with a population of } 270,000 \text { (with } \\ \text { Newcastle } & \text { an additional } 90,000 \text { people commuting to the city }\end{array}$ each day Newcastle is ranked as the 20th most deprived district in England.

Consisting of several town centers with a population of around 190,000. It has been associated in the past with seaside tourismand heavy industry. However, these have declined over the last 30 years and the district is undergoing a slow regeneration. It is the 80th most deprived district in England and Wales.

One of the largest counties in England. It is a predominantly rural area. Although the county has a population of 310,000 , no urban area within its

Northumberland boundaries has more than 35,000 people. As an average across the local authorities within Northumberland it carries a score of 138th most deprived district in England.

The smallest district in the study area, covering just $64 \mathrm{~km}^{2}$, with a population of around 150,000 . Similar to North Tyneside, its history is dominated by heavy industry, particularly in shipbuilding;coal mining and engineering and also similarly, these have

South Tyneside significantly declined since the 1980s to leave large pockets of deprivation. South Tyneside is the $27^{\text {th }}$ most deprived district in England and $60 \%$ of the population live in ward ranked in the 25 percent most deprived in England.

Sunderland has a population of 280,000 and is the $22^{\text {nd }}$ most deprived district in the country with $46 \%$ of

Sunderland the population living in the $20 \%$ most deprived areas in England. Much of the deprivation has its origins in the decline in heavy industry, particularly shipbuilding, coal-mining and glass-making. 
acteristics). Yet knowledge and access to these sex markets is limited, and effectively remains "hidden" to many professionals in the public and voluntary sectors. By which we mean that despite evidence that such markets exist, the lack of a "knowledge network" leads to limited sharing of information and expertise between sectors and agencies, which in turn allows the extent of the sex market to remain largely concealed. Below we provide a narrative about the development of a methodology that responded to these issues.

Our involvement with sex market research in the study area dates back to 2005, when Safe Newcastle (the local Crime and Disorder Reduction Partnership) began the implementation of their three-year community safety strategy. Safe Newcastle commissioned Barefoot Research and Evaluation to consult with a range of community and interest groups, local residents and frontline agencies about community safety and the Crime and Disorder Reduction Partnerships (CDRPs) response.

This exercise was intended to inform the service response and measure the impact of the strategy from a "user's perspective". During this earlier research, the issue of sex markets and prostitution was increasingly mentioned by a series of different and unconnected organizations and individuals. However, little was collectively known and what was known was attributed to anecdote and rumor. A knowledge mapping approach is suggested by the UK Home Office (2006: p. 14) Coordinated Prostitution Strategy, which stated that local partnerships take the following actions to tackle prostitution:

Where prostitution is an issue locally... A first step will be to map the nature and extent of the issues locally and to develop an understanding of the complexity of the impact of prostitution, and then consider ways to address it.

Indeed, one of the primary functions of CDRPs is information exchange, and as Creech \& Willard (2001: p. 19) note, there has been an increasing interest in the value of knowledge network models over the last 10 years or so as a means of enabling statutory, non-statutory and private sector partnerships, where the whole is greater than the sum of the parts. They define knowledge networks as agencies "working together on a common concern, to strengthen each other's research and communications capacity, to share knowledge bases and develop solutions that meet the needs of target [groups]" By bringing together "knowledge nodes" across a range of statutory and nonstatutory agencies it was hoped that a knowledge network of sex markets in the region would emerge.

\section{Methods}

\section{Devising the Methodology}

Developing a methodology for this study was initially problematic. We realized early on that recruiting sex workers for the study would be difficult as the visible sex market in the study area was geographically dispersed and hard to access. There was also only one small drop-in service for sex workers in a church in Newcastle (started in 2006) where relationships were being built up between the service and a small group of women. This meant that an obvious route to gain access to sex workers via support services was not available (Melrose, 2002; Sanders, 2005). Moreover, the primary researcher was male, and as Hubbard (1999: p. 231) reflects, it is often difficult for a man to investigate female sex work without it "becoming anything more than a masculine attempt to appropriate the feminine 'other'",
With this in mind, we decided to create two parts to the study: phase I, a short knowledge mapping exercise to scope the research task, based on interviews with professionals and practitioners (from a range of agencies) likely to have contact with sex workers; phase II, direct interviews with sex workers.

For the knowledge mapping phase we interviewed 150 professional/practitioner respondents face to face and 50 by telephone. They came from a range of statutory and voluntary and community sector agencies, including: sexual health services (for example, Genito Urinary Medicine (GUM) clinics and contraception services); child protection nurses; teenage pregnancy services; children's services; Social Services; drug support agencies, including harm reduction and treatment services; asylum seeker and refugee services; youth and community services, including outreach housing and accommodation providers; services for sex workers; services for lesbian, gay, bisexual and transgendered people; services for victims of rape; central government representatives; Crime and Disorder Reduction Partnerships (CDRPs); Local Safeguarding Children Boards (LSCBs) and Northumbria Police. Respondents were asked a series of questions about their knowledge of the extent, characteristics and magnitude of the sex market and we only counted sex workers when the respondent had direct experience of working with that person.

We asked professionals a series of questions about their knowledge of the extent, characteristics and magnitude of the sex market. They were asked how many people they were aware of who were involved in sex work, what type of sex work that was and how they knew this. We only counted sex workers when the professional had direct experience of working with that person. We used a consistent line of questioning to arrive at the data presented in this study. The questions we asked included:

1) Do you have any knowledge of what type of sex work goes on in the area?

2) In the last year, do you know of any of your clients or service users that have exchanged sex for resources (money, drugs, alcohol, accommodation, etc.)?

3) How do you know this (have they told you) or do you suspect (and why do you suspect)?

4) Do you know how or why they became involved?

5) Are you aware of any travelling for sex work/sexual exchanges?

6) Do you provide any services to sex workers? Is this any different to you routine services?

7) Do you know of anyone who provides services to sex workers?

8) Do you know the needs of sex workers in the area?

9) Do you have any concerns in relation to sex work in the area?

The research used "snowballing techniques", i.e. asking professionals who else they thought we should talk to, and in this way we covered the majority of relevant people. Snowball sampling is particularly effective in locating members of hard to reach populations where the focus of the study is on a sensitive issue (Hendricks \& Blanken, 1992). We had confidence with this approach as, towards the end of the research in each area, we reached "saturation" where people were mentioning the same set of names so we felt we had covered the most relevant agencies. Many professionals were also approached both on the telephone and in person who had no knowledge of sexual exploitation or sex markets and essentially proved to be 
"blind alleys". To those we interviewed, we guaranteed confidentiality and anonymity. If we had not done this, we would not have been able to collect the quality and level of data that we were able to. We have only gathered information on the extent of sex work, not the outcomes (i.e. what has happened to the person identified). We did ensure that every individual, particularly under 18 year olds, were known to the relevant services (the Police or Children's or Adult Services).

Data were analyzed using the grounded theory-constant comparison method, where each item is compared with the rest of the data to establish and refine analytical categories (Pope et al., 2000). Themes emerged within individual interviews and across different interviews. Recurring themes across transcripts were taken to reflect shared understandings of the participants (Smith and Marshall, 2007).

\section{Developing the Methodology}

The first question we asked respondents was always "what type of sex work takes place in the area?" A common response to this question was "there's no sex work, no street prostitution around here... it's not like Middlesbrough ${ }^{3}$ [a city in the North East of England with highly visible sex markets]”.

We then clarified what we meant by sex work (any sexual act exchanged for a commodity, for example drugs, money, alcohol, status, goods, accommodation) and in the discussion that followed this usually resulted in a realization amongst the professionals that, yes, they were aware of particular clients who may have exchanged sex for somewhere to stay or for drugs. We then asked, "amongst your client group in the last year, how many people can you think of that engaged in such work?” A respondent from harm reduction service (SM63), for example, noted that "yes, I can think of at least three clients who I know of, and another three who I strongly suspect were, because they were picking up more condoms than you would use every two weeks, or their boyfriends were”. Data obtained were triangulated through interviews with other agencies involved with similar client groups both within and outside the areas. This helped us to verify findings and minimize double counting ${ }^{4}$.

After several interviews it became apparent that we would have to broaden our definition of sex work to include the sexual exploitation of children, as many agencies reported knowledge of under 18 year olds being involved in prostitution. Yet as one professional (SM67) told us "I don't think it's taken seriously by professionals... it's the 16 to 18 year olds who are the problem... the professionals think that once they're older they bring it on themselves... two weeks after X was raped, she couldn't

\footnotetext{
${ }^{3}$ Middlesbrough has a reputation as the North-East's prostitution capital. According to Strange (2005) Prostitution in Middlesbrough goes back many years. Although the town's heavy industry dwindled prostitutes continued to work in the traditional areas near to the old dock area on the north fringe of the town. During the early to mid 90's the prostitution scene in Middlesbrough changed considerably. The numbers involved in prostitution increased substantially to an estimated 250 sex workers, a rise which appeared to coincide with increased availability of heroin locally (Middlesbrough has one of the lowest street heroin prices in the country).

${ }^{4}$ With a drug treatment service (SM25, SM26, SM27), for example, we asked how many of the clients who they knew or strongly suspected of engaging in sex work, how many of these would be likely to access harm reduction services or any other services.

${ }^{5}$ We are aware of the discourse that suggests that all prostitutes are exploited thus ignoring the fact that, as Hubbard (2004) argues, many work interpedently on their own terms.
}

walk very well, she was showing me a Playboy thong that she'd bought to go out in... she's not making good decisions”.

We use the term sexual exploitation ${ }^{5}$ as the 2003 Sexual Offences Act stipulates that people under 18 are victims not perpetrators, i.e. they are treated as being sexually exploited rather than selling sex. Similar to our definition of sex work, we decided the sexual exploitation of children includes cases where a young person (between 13 and 18 years old) exchanged sex for money with an adult. It must be noted that all those children we did identify were already known to the Police, social services or LSCBs in the areas.

\section{Results}

\section{Sex Markets in Northumberland and Tyne \& Wear}

The summary findings of our knowledge mapping research are presented below. We then go on to triangulate these findings within the context of the Voices Heard research discussed earlier. We do this in order to demonstrate the validity and reliability of our findings viz-a-viz researching sex work with a knowledge mapping approach.

Sex work in the UK is a varied and diverse area, but similar to other studies of UK sex market characteristics (Hunter et al, 2004) our research indicates a broad typology of sex markets: a high section, which includes workers attached to certain agencies or independent workers who charge relatively high fees for their services. A middle section, which includes independent workers, those attached to escort agencies ("out call”) and those working in brothels ("in-call"). People working in this section of the market can be "career" sex workers, or many simply drift in and out of it over considerable periods of time (when they need the cash). This multinational group make up the majority of sex workers in the area.

The low section includes problematic drug users, failed asylum seekers and those working on the streets and in crack houses. These groups are extremely vulnerable and have varying degrees of involvement in sex work, from full time to occasional. This section is characterized by "survival sex work", which we define as the practice of exchanging sex not only for money but also for a range of essential resources such as accommodation, drugs, food, laundry and tobacco (see Voice Heard, 2007; Hartworth, 2009). A respondent working for Northumbria Police (SM09) had this to say about this group:

\footnotetext{
“All sex workers can fall foul of 'dodgy punters' but it is the girls that make up this section that are at most risk. These girls operate on a local basis, occasionally working on the streets or exchanging sex for a roof over their heads."
}

As stated, however, this is a broad categorization, and the reality is likely to be more fluid and dynamic. For example, SM20, a project manager for a sex worker support project in Newcastle noted that:

"There are different layers to the sex industry in Tyne and Wear. Some may work independently or for escort agencies and charge high fees for their services. This group's involvement in sex work is unlikely to relate to social exclusion factors. Others may be involved in what could be described as survival sex and their involvement in sex work relates directly to homelessness, drug and alcohol dependency, failed asylum claims, etc... In my experience, 
there are not three distinct strands but there is one extreme to the other with everything in between."

Similar to sex market typology, it is very difficult to quantify the sex working population (Cusick et al., 2009; Hunter et al., 2004). Our research indicates that approximately 1000 people across the study area are involved in sex work to some degree at any one time. This can be contrasted with estimates of between 48,000 to 80,000 sex workers in the UK.

We found that the Internet was a common medium used for advertising by sex workers. This is an increasingly common trend, as Cameron (2004: p. 1654) notes, anyone with a credit card and modest search engine abilities can access porn images and buy sex toys in a very short space of time. Significantly, Hubbard (2004) argues that the use of websites to locate sex workers “off-street” helps to make prostitution appear invisible.

These web-based sex workers could be divided into two groups: independent individuals selling sex (80\% of cases), often from their own premises; and individuals working for someone else, usually a partner, an escort agency or pimp (20\% of cases). Independent individuals selling sex either had their own websites, or more commonly had their contacts and adverts on other "adult" websites. These sex workers usually worked from a specific location for "in calls", though many stated on their websites that they travelled for "out calls" throughout the region.

Placing adverts in newspapers (including The Ad Mag and The Sport) was a common practice for escort agencies, individuals and brothels. For example, one professional (SM04) discussed an 18-year-old female who lives in a B\&B. She has been sexually exploited since she was 14 years old and is now pimped by her father and brother who also live in the same $\mathrm{B} \& \mathrm{~B}$. She works from the B\&B and advertises on both the Internet and in The Sport. It was reported that "she doesn't like having sex without a condom but is sometimes forced to... her father or brother negotiate a price with the customer over the phone on her behalf”.

There are increasing reports of street sex work and escort agencies producing advertising material to recruit sex workers (posted through doors-see Figure 2). Escort agencies were typically the same as those advertised on the Internet. Individuals advertising in the papers may also have websites or more commonly advertise on adult contact websites.

We found evidence of a remarkable variation in the prices of sex, from $£ 10$ in crack houses to $£ 650$ for an overnight stay with an escort (Table 2). As already discussed money is often not the means of exchange, sex workers may also exchange sex for drugs, food and lodging, a system where sex work is a survival strategy fulfilling a range of needs rather than just access to finance.

The space in which sex work takes place is an integral part of why and how sex is sold in certain streets of cities and towns. Cameron (2004) suggests a typology of urban sex market maturity, including sporadic sex economy, partially laddered sex economy and a mature sex economy. He cites the establishment of a 'Spearmint Rhino' lap dancing club in a regenerated inner-city area of Birmingham as an indication of a developing mature sex market in the UK. However, both Hubbard (2004) and Sanders (2004: p. 1705) argues that sex work locations are frequently the target of resources from public services, especially the growth of multi-agency partnerships and forums created to act upon what has historically been considered spoiled identities associated with drugs, disease, dysfunctional families

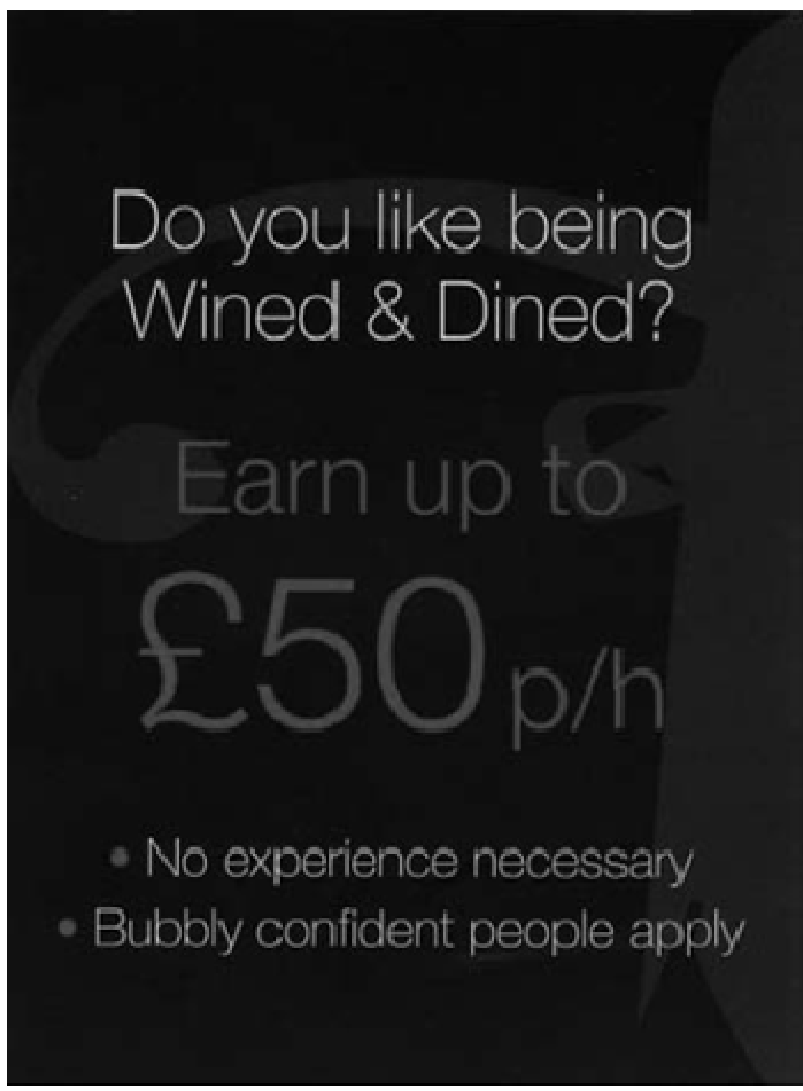

Figure 2.

Recruiting flyer for escort agency.

Table 2.

The price of sex in the study area.

\begin{tabular}{lll}
\hline The price of sex & With condom & Without condom \\
\hline \multirow{3}{*}{ Full sex (penetrative vaginal sex) } & $\begin{array}{l}\text { Highest } £ 150 \\
\text { Lowest } £ 5\end{array}$ & Highest $£ 100$ \\
& Average $£ 37$ & Lowest $£ 10$ \\
& Average $£ 34$ \\
Oral sex & Highest $£ 100$ & Highest $£ 100$ \\
& Lowest $£ 3$ & Lowest $£ 5$ \\
& Average $£ 18$ & Average $£ 15$ \\
Hand job & Highest $£ 30$ & Highest $£ 30$ \\
& Lowest $£ 2$ & Lowest $£ 2$ \\
Anal sex & Average $£ 11$ & Average $£ 11$ \\
& Highest $£ 100$ & Highest $£ 100$ \\
& Lowest $£ 5$ & Lowest $£ 10$ \\
Average $£ 30$ & Average $£ 32$ \\
\hline
\end{tabular}

and danger. Hubbard (2004) cites the persistence of discourses that associate sex work with crime and help perpetuate the idea that sex work is a genuine threat to the quality of urban life. Thus despite the trend towards sex market maturity outlined by Cameron above, it is frequently the case in provincial UK cities that locations where sex work takes place are "low value" (Cameron, 2004) and have a "very run down, derelict feel" (McKeganey, 2006: p. 153).

The study areas were typified by geographically dispersed sex markets, with street-based sex work identified in car parks, bus interchanges, around hostels, pubs and on the streets. In particular, the on-street market in Newcastle is different to the 
traditional image of the "red light area". There are areas that have been traditionally associated with on-street sex and continue that association, such as the area around Central Station, but there are also new, often transient, areas connected to onstreet sex workers. For example, we received reports of under-18 year old males soliciting around the Metro Radio Arena and the area known as "the Gardens" in Newcastle (although this area is less used now due to nearby housing redevelopments). There have been cases of young men from care homes, often with significant mental health problems, soliciting in these areas and exchanging sex for cigarettes. There is also evidence of heterosexual males with problematic drug use selling sex to gay men in these areas.

The occasional nature of some sex work ${ }^{6}$ explains characteristics of street work in certain areas; they are not permanent street markets but are areas where purchasers of sex can be found, the sporadic sex economy described by Cameron (2004), where sex workers may run either "poor-quality establishments" or sell their bodies on the streets in unsafe, low-value economic spaces. For example, one project worker (SM15) said "There was one woman who had a bad injecting injury and I had to take her to a Newcastle hospital. We went at $5.30 \mathrm{pm}$ and left at $10.30 \mathrm{pm}$; she was getting really stressed that the shops had closed and she couldn't go shoplifting and she said she'd have to go to the bus station to sleep with a dirty man". There are other locations across the study area that are not places where "punters" go to buy sex, but are places where sex workers know they can go if they need to sell sex.

We also received detailed reports from services about their clients being involved in sex work. These include:

- Contraceptive and Sexual Health (CASH) services in two out of the six areas where between five and six individuals were reported to be known to be sex workers.

- Harm reduction services (such as needle exchanges) throughout the region consistently reported that a significant number of their female caseload and some of their male clients occasionally or regularly exchanged sex for drugs or money for drugs. Many of these services across the region have high caseloads, for example, 150 active service users (those accessing their service at least once a month or more). This is consistent with Bellis et al., (2007) who identified than $85 \%$ of the sex workers they interviewed were drug users, and Church et al., (2001), who found that around 90\% UK street sex workers had used an illegal drug in the past 6 months (see also Gilchrist et al., 2005; El-Bassel et al., 2001; McKeganey, 2006; Hester \& Westmarland, 2004).

- Drug treatment and support services across the region also consistently reported that they knew of service users who were involved in sex work.

- GUM clinics across the region reported that sex workers regularly access their services, both male and female. Significantly, a GUM clinic professional (SM33) stated that the figures or knowledge that they have are underestimates.

- Women support services across the region identified individuals in their caseload who were sex workers, ranging from sex work as the sole means of paying for drugs to occasional sex work.

\footnotetext{
${ }^{6}$ Whilst the number of problematic drug users involved in sex work is high, many would not identify themselves as sex workers. They will occasionally, although regularly, exchange sex for drugs or money for drugs and often accommodation. Some women may rarely engage in sex work for money when they need desperately to buy drugs.
}

- Asylum seeker and refugee services across the region report that many destitute failed asylum seekers exchange sex for accommodation and other essential resources.

- Housing providers such as emergency accommodation, B\&Bs or hostels had knowledge about their clients involved in sex work, for money, alcohol, drugs or status.

\section{Discussion}

The findings presented in the previous section are based on a knowledge mapping approach where professionals and practitioners (from a range of agencies) likely to have contact with sex workers were interviewed (rather than sex workers themselves). Whilst the primary focus of this paper is methodological, our findings are remarkably similar to the Voices Heard (2007) research in terms of numbers of people involved, the types of sex work and exploitation and the themes associated with the marginalized groups (for example, low self esteem, high levels of problematic drug use, frequency of violence, significant health and mental health issues). As might be expected, such findings are consistent with other sex work research (Gossop et al., 1994; May et al., 2000; El-Bassel et al., 2001; Gilchrist et al., 2005; Saunders, 2005; Tomura, 2009; Mosedale, 2009).

The peer-led approach of the Voices Heard research provides a perspective from the ground, which complemented our perspective "from above". It also added validity to our methodology by confirming our findings. We would argue, therefore, that when questioned sensitively, with a strong rationale behind the study (i.e. to improve knowledge and services to a marginalized group and to develop policy) individual professionals have considerable knowledge about sex work and exploitation within their client group which can be used to map the nature and extent of sex markets. We also feel that this methodology can be replicated at reasonably low cost by other agencies (both statutory and non-statutory) interested in understanding the characteristics of sex markets. This in turn opens up the ability to carry out research with difficult target groups. Moreover, as the primary researcher was male, it was clearly impossible to conduct a female-centered approach (Boynton, 2002; Sanders, 2004; Tomura, 2009).

Whilst we are confident about our methodological approach, we do recognize that there are limits to our methodology, specifically in terms of relying upon the testimony of others as a data source. When we documented the direct professional knowledge of those interviewed we accepted it as 'the truth'. We had no reason to doubt the integrity of the reports of professionals about their client group. Therefore, one of the limits to the methodology is this level of trust. However, we would argue that our large dataset of 200 interviews gives both legitimacy and consistency to our findings, and has allowed us to cross-reference interview material across a range of agencies and locations.

Moreover, the study was carried out across six local authority areas, a consistent line of questioning was used and the findings from key agencies were broadly similar, for example, drug harm minimization services, GUM clinics and looked after children's services all reported similar contact with sex workers and young people who were known to be sexually exploited.

Mapping urban sex markets via professionals is a valid methodology and one that can be used in other areas. The results are grounded in the professional experience of the participants and present an important case study of "hidden" sex mar- 
kets. Many agencies still fail to understand the range of needs faced by sex workers (Church et al., 2001; Smith \& Marshall, 2007). We believe that mapping knowledge in this way has the potential to deliver more appropriate and specific policy interventions. After Creech \& Willard (2001) we would argue that the rationale for investing in sex market knowledge management include filling the knowledge gaps that inhibit good policy practice and learning from each other across sectors and regions about best practices.

We have identified that the small visible sex market in the Northumbria Police Force Area provides only an indication of a much bigger exchange system. We have briefly outlined some of the factors leading to what Hubbard (2004) terms an increasingly invisible urban sex market. If we are to truly open a public debate on sex work, then as Shaver (2005) correctly points out, a continued focus on sex work and sex workers will help make it, and them, more visible. A key element to such a continued focus is being able to use a methodology that is quick, relatively cheap, user friendly and valid. Mapping sex markets, as described in this paper, can provide a useful source of data, which may be used as a baseline to develop further empirical research or for triangulation with existing research. However, when findings are produced and shared, there must be an openness to consider and act upon them.

As already discussed, our mapping work corroborates the findings of the Voices Heard study. Indeed, once we had triangulated our data with the results of the Voices Heard study, we were so confident about our findings that we decided Phase II of the project (individual interviews with sex workers) was unnecessary. Strong links were found between sex work and issues such as drug misuse, mental and physical health and the use of services. Many sex workers suffered economic, housing, health, social and physical vulnerabilities. We have also found significant evidence of a range of people involved and many different types of market. What is of most concern, however, is the number of marginalized and vulnerable men and women who are involved. Sex work for this group is mostly linked to problematic drug use and consequently is associated with high levels of criminality, health risk both to themselves and others and risk of death and violence. This group is the most difficult to reach but their needs are amongst the greatest in society.

These themes have implications for statutory and voluntary services, not only in the UK but also in international contexts where it is necessary to understand the dynamics of hidden or hard to reach groups. Despite increasing calls for more open public debate on sex work and prostitution, our experience is that this remains a complex and restricted research area in the UK.

As Hunter et al. (2004) argue, before any service commissioning decisions are made, a detailed mapping of the local situation should be undertaken to establish what type of sex market there is. We would argue that the knowledge mapping outlined in this paper is fully defensible, reliable and replicable and represents an important step both in terms of furthering the debate and developing a knowledge network of closer statutory and non-statutory agency working.

\section{Acknowledgements}

We are grateful to the Northern Rock Foundation for funding this research. The views expressed in the study are those of the authors and not necessarily those of the Northern Rock Foundation.

\section{REFERENCES}

Annandale, D. (2005). Call me Elizabeth. London: Times Warner Books. Barefoot Research \& Evaluation. (2008). Hidden markets: Sex work in Northumberland and Tyne \& Wear. Northern Rock Foundation. URL (last checked 2 February 2012).

http://Www.Barefootresearch.Org.Uk/Think\%204.Pdf

Bellis, M., Watson, F., Hughes, S., Cook, P. A., Downing, J. Clark, P., \& Thomson, R. (2007). Comparative views of the public, sex workers, businesses and residents on establishing managed zones for prostitution: Analysis of a consultation in Liverpool. Health \& Place, 13, 603-616. doi:10.1016/j.healthplace.2006.08.001

Boynton, P. M. (2002). Life on the streets: The experiences of community researchers in a study of prostitution. Journal of Community \& Applied Social Psychology, 12, 1-12. doi:10.1002/casp.657

Church, S., Henderson, M., Barnard, M., \& Hart, G. (2001). Violence by clients towards female prostitutes in different work settings: Questionnaire survey. British Medical Journal, 322, 524-525. doi:10.1136/bmj.322.7285.524

Creech, H., \& Willard, T. (2001). Strategic intentions: Managing knowledge networks for sustainable development. Winnipeg: International Institute for Sustainable Development.

Coyle, D. (2001). Legalizing prostitution could raise £250m tax. URL (last checked 21 March 2011).

Http://www.Independent.Co.Uk/News/Uk/This-Britain/Legalising-Pr ostitution-Could-Raise-Pound250m-Tax-680850.Html

Cusick, L., Kinnell, H., Brooks-Gordon, B., \& Campbell, R. (2009). Wild guesses and conflated meanings? Estimating the size of the sex worker population in Britain. Critical Social Policy, 29, 703-719. doi:10.1177/0261018309341906

De Speigel. (2011). Sex tax machine introduced for Bonn prostitutes. De Speigel Online. URL (last checked February 2012). http://www.spiegel.de/international/germany/0,1518,783438,00.html

Efthimiou-Mordant, A. (2002). Sex working drug users: Out of the shadows at last. Feminist Review, 72, 82-83.

doi:10.1057/palgrave.fr.9400048

El-Bassel, N., Simoni, J. M., Cooper, D. K., Gilbert, L., \& Schilling, R. F. (2001). Sex trading and psychological distress among women on methadone. Psychology of Addictive Behaviors, 15, 177-184. doi:10.1037/0893-164X.15.3.177

Elmore-Meegan, M., Conroy, R., \& Agala, B. (2004) Sex workers in kenya, numbers of clients and associated risks: An exploratory survey. Reproductive Health Matters, 12, 50-57. doi:10.1016/S0968-8080(04)23125-1

Gilchrist, G., Gruer, L., \& Atkinson, J. (2005). Comparison of drug use and psychiatric morbidity between prostitute and non-prostitute female drug users in Glasgow, Scotland. Addictive Behaviors, 30, 1019-1023. doi:10.1016/j.addbeh.2004.09.003

Gossop, M., Powes, B., Griffiths, P., \& Strang, J. (1994). Sexual behavior and its relationship to drug-taking among prostitutes in South London. Addiction, 89, 961-970. doi:10.1111/j.1360-0443.1994.tb03356.x

Griffiths, P., Gossop, M., Powis, B., \& Strang, J. (2006). Reaching hidden populations of drug users by privileged access interviewers: Methodological and practical issues. Addiction, 88, 1617-1626. doi:10.1111/j.1360-0443.1993.tb02036.x

Gysels, M., Pool, R., \& Nnalusiba, B. (2002). Women who sell sex in a ugandan trading town: Life histories, survival strategies and risk. Social Science \& Medicine, 54, 179-192. doi:10.1016/S0277-9536(01)00027-2

Hartworth, C., Hartworth, J., \& Baxter, R. (1998). The informal economy in Newcastle. Newcastle Upon Tyne: The Big Issue.

Heap, C. (2003). The city as a sexual laboratory: The queer heritage of the Chicago school. Qualitative Sociology, 26, 457-487. doi:10.1023/B:QUAS.0000005052.77181.51

Heckathorn, D. (1997). Respondent-driven sampling: A new approach to the study of hidden populations. Social Problems, 44, 174-199. doi:10.1525/sp.1997.44.2.03x0221m

Hendricks, V. M., \& Blanken, P. (1992). Snowball sampling: Theoretical and practical considerations. In V. M. Hendricks, P. Blanken, \& N. Adriaans (Eds.), Snowball sampling: A pilot study on cocaine use 


\section{HARTWORTH ET AL.}

(pp. 17-35). Rotterdam: IVO.

Hester, M., \& Westmarland, N. (2004). Tackling street prostitution: towards a holistic approach. Home Office Research Study No. 279. London: Home Office.

Hill, C. (1972). The world turned upside down: Radical ideas during the English revolution. London: Temple Smith.

Home Office. (2006). A coordinated prostitution strategy. London: Home Office.

Howell, P., Beckingham, D., \& Moore, F. (2008). Managed zones for sex workers in Liverpool: Contemporary proposals, Victorian parallels. Transitions Institute of British Geographers, 33, 233-250. doi:10.1111/j.1475-5661.2008.00292.x

Hubbard, P. (1999). Researching female sex work: Reflections on geographical exclusion, critical methodologies and "useful" knowledge, Area, 31, 229-237. doi:10.1111/j.1475-4762.1999.tb00087.x

Hubbard, P. (2004). Cleansing the metropolis: Sex work and the politics of zero tolerance. Urban Studies, 41, 1687-1702. doi:10.1080/0042098042000243101

Hubbard, P., Matthews, R., \& Scoular, J. (2008). Regulating sex work in the EU: Prostitute women and the new spaces of exclusion. Gender Place and Culture, 15, 137-152. doi:10.1080/09663690701863232

Hunter, G., May, T., \& The Drug Strategy Directorate (2004). Solutions and strategies drug problems and street sex markets. London: Home Office.

Landale, S. (2005). Off-street prostitution and drug use in the north east. Drug Interventions Programme, Newcastle upon Tyne: Government Office North East.

Lewis, J., \& Maticka-Tyndale, E. (2000). Licensing sex work: Public policy and women's lives. Canadian Public Policy/Analyse De Politiques, 26, 437-449.

May, T., Edmunds, M., \& Hough, M. (1999). Street business: The links between sex and drug markets. Police Research Series Paper 118. London: Home Office.

Mckeganey, N. (2006). Street prostitution in Scotland: The views of working women. Drugs, Education, Prevention and Policy, 13, 151166. doi:10.1080/09687630500412312

Melrose, M. (2002). Labour pains: Some considerations on the difficulty of researching juvenile prostitution. International Journal of Social Research Methodology, 5, 333-351. doi:10.1080/13645570110045963

Moffatt, P. G., \& Peters, S. A. (2004). Pricing personal services: An empirical study of earnings in the UK prostitution industry. Scottish Journal of Political Economy, 51, 675-690. doi:10.1111/j.0036-9292.2004.00327.x

Mosedale, B., Kouimtsidis, C., \& Reynolds, M. (2009). Sex work, substance misuse and service provision: the experiences of female sex workers in South London. Drugs: Education, Prevention and Policy, 16, 355-363. doi:10.1080/09687630701579679

O'Neill, M. (1996). Researching prostitution and violence: Towards a feminist praxis. In M. Hester, L. Kelly, \& J. Radford (Eds.), Women, Violence and Male Power. London: Open University Press.

O’Neill, M., Campbell, R., Hubbard, P., Pitcher, J., \& Scoular, J. (2008). Living with the other: Street sex work, contingent communities and degrees of tolerance. Crime, Media, Culture, 4, 73-93.

Pitcher, J., Campbell, R., Hubbard, P., O’Neill, M., \& Scoular, J. (2006). Living and working in areas of street sex work: From conflict to coexistence. Bristol: Policy Press.

Parsons, J. A., Johnson, T. P., Warnecke, R. B., \& Kaluzny, A. (1993). The effect of interviewer characteristics on gatekeeper resistance in surveys of elite populations, Evaluation Review, 17, 131-143. doi:10.1177/0193841X9301700201

Pasco, L. (2002). Naked power: The practice of stripping as a confidence game. Sexualities, 5, 49-66. doi: $10.1177 / 1363460702005001003$

Pope, C., Ziebland, S., \& Mays, N. (2000). Qualitative research in health care: Analysing qualitative data. British Medical Journal, 320, 114116. doi:10.1136/bmj.320.7227.114

Porter, J., \& Bonilla, L. (2000). Drug use, HIV and the ecology of street prostitution. In R. Weitzer (Ed.), Sex for sale. London: Routledge.

Pyett, P. (1998). Doing it together: Sex workers and researchers in research for sex work. Amsterdam: Vrije Universiteit.

Rothschild, N. (2009). Who says sex workers want to be "saved”? The Guardian. URL (last checked 16 November 2011). http://www.Guardian.Co.Uk/Commentisfree/2009/Mar/13/Prostitutio n-Humantrafficking

Rubin, H., \& Rubin, I. (2004). Qualitative interviewing: The art of hearing data. London: Sage.

Salganik, M. J., \& Heckathorn, D. D. (2004). Sampling and estimation in hidden populations using respondent-driven sampling. Sociological Methodology, 34, 193-239. doi:10.1111/j.0081-1750.2004.00152.x

Sanders, T. (2005). The risks of street prostitution: punters, police and protesters. Urban Studies, 41, 1703-1717. doi:10.1080/0042098042000243110

Sanders, T. (2005). Sex work-A risky business. Abingdon: Willan Publishing.

Sanders, T. (2006). Sexing up the subject: Methodological nuances in the female sex industry, Sexualities, 9, 449-468. doi:10.1177/1363460706068044

Scott, J., Minichiello, V., Marino, R., Harvey, G., Jamieson, M., \& Browne, J. (2005). Understanding the new context of the male sex work industry. Journal of Interpersonal Violence, 20, 320-342. doi:10.1177/0886260504270334

Shaver, F. (2005). Sex work research, methodological and ethical challenges. Journal of Interpersonal Violence, 20, 296-319. doi: $10.1177 / 0886260504274340$

Smith, F. M., \& Marshall, L. A. (2007). Barriers to effective drug addiction treatment for women involved in street-level prostitution: A qualitative investigation. Criminal Behaviour and Mental Health, 17, 163-170. doi: $10.1002 / \mathrm{cbm} .654$

Soothill, K., \& Sanders, T. (2004). Calling the tune? Some observations on paying the price: A consultation paper on prostitution. The Journal of Forensic Psychiatry \& Psychology, 15, 642-659. doi:10.1080/14789940412331317959

Strange, G. (2005). Multi-agency action against prostitution project. Middlesbrough police district. MAP Project Report.

Surratt, H., Inciardi, J., Kurtz, S., \& Kiley, M. (2004). Sex work and drug use in a subculture of violence. Crime and Delinquency, 50, 4349. doi:10.1177/0011128703258875

Tomura, M. (2009). A prostitute's lived experiences of stigma. Journal of Phenomenological Psychology, 40, 51-84. doi:10.1163/156916209X427981

Voices Heard. (2007). Hidden for survival: Peer research into the lives of sex workers within Newcastle, Gateshead, Sunderland, South Tyneside and North Tyneside. Newcastle upon Tyne and Sunderland: Tyneside Cyrenians and Counted 4.

Wahab, S. (2003). Creating knowledge collaboratively with female sex workers: insights from a qualitative feminist and participatory study. Qualitative Inquiry, 9, 625-642. doi:10.1177/1077800403252734

Ward, H., Mercer, C. H., Wellings, K., Fenton, K., Erens, B., Copas, A., \& Johnson, A. M., (2005). Who pays for sex? An analysis of the increasing prevalence of female commercial sex contacts among men in Britain. Sexually Transmitted Infections, 81, 467-471. doi:10.1136/sti.2005.014985

West, J. (2000). Prostitution: Collectives and the politics of regulation. Gender, Work and Organisation, 7, 106-118. doi:10.1111/1468-0432.00098 